\title{
Diagnosis and Therapy of Female Pelvic Organ Prolapse. Guideline of the DGGG, SGGG and OEGGG (S2e-Level, AWMF Registry Number 015/006, April 2016)
}

\author{
Diagnostik und Therapie des weiblichen Descensus genitalis. Leitlinie der DGGG, \\ SGGG und OEGGG (S2e-Level, AWMF-Registernummer 015/006, April 2016)
}

Authors

Affiliations
K. Baeßler ${ }^{1}$, T. Aigmüller ${ }^{2}$, S. Albrich ${ }^{3}$, C. Anthuber ${ }^{4}$, D. Finas ${ }^{5}$, T. Fink ${ }^{6}$, C. Fünfgeld ${ }^{7}$, B. Gabriel ${ }^{8}$, U. Henscher ${ }^{9}$, F. H. Hetzer ${ }^{10}$, M. Hübner ${ }^{11}$, B. Junginger ${ }^{1}$, K. Jundt ${ }^{12}$, S. Kropshofer ${ }^{13}$, A. Kuhn ${ }^{14}$, L. Logé ${ }^{15}$, G. Nauman ${ }^{16}$, U. Peschers ${ }^{17}$, T. Pfiffer $^{18}$, O. Schwandner ${ }^{19}$, A. Strauss ${ }^{20}$, R. Tunn ${ }^{21}$, V. Viereck ${ }^{22}$

The affiliations are listed at the end of the article.
Key words

- pelvic organ prolapse

- stress urinary incontinence

- pelvic floor

- surgical therapy

- physiotherapy

pessary treatment

Schlüsselwörter

- genitaler Deszensus

- Belastungsinkontinenz

- Beckenboden

- operative Therapie

- Physiotherapie

- Pessare

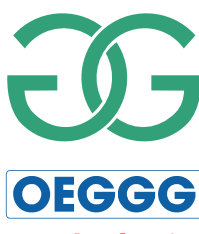

gynécologie suisse

\section{Deutsche Version unter: http://dx.doi.org/ 10.1055/s-0042-119648 \\ received $\quad 22.10 .2016$ revised 22.10.2016 accepted 22.10.2016 \\ Bibliography \\ DOI http://dx.doi.org/ \\ 10.1055/s-0042-119648 \\ Geburtsh Frauenheilk 2016; 76 \\ 1287-1301 ๔ Georg Thieme \\ Verlag KG Stuttgart · New York} ISSN 0016-5751

\section{Correspondence}

PD Dr. med. Kaven Baeßler

Charité

Centrum Frauen-, Kinder- \& Jugendmedizin mit Perinatalzentrum \& Humangenetik Hindenburgdamm 30

12203 Berlin

Germany

kaven.baessler@charite.de

\section{Abstract \\ $\nabla$}

Aims: The aim was to establish an official interdisciplinary guideline, published and coordinated by the German Society of Gynecology and Obstetrics (DGGG). The guideline was developed for use in German-speaking countries. In addition to the Germany Society of Gynecology and Obstetrics, the guideline has also been approved by the Swiss Society of Gynecology and Obstetrics (SGGG) and the Austrian Society of Gynecology and Obstetrics (OEGGG). This is a guideline published and coordinated by the DGGG. The aim is to provide evidence-based recommendations obtained by evaluating the relevant literature for the diagnostic, conservative and surgical treatment of women with female pelvic organ prolapse with or without stress incontinence.

Methods: We conducted a systematic review together with a synthesis of data and meta-analyses, where feasible. MEDLINE, Embase, Cinahl, Pedro and the Cochrane Register were searched for relevant articles. Reference lists were handsearched, as were the abstracts of the Annual Meetings of the International Continence Society and the International Urogynecological Association. We included only abstracts of randomized controlled trials that were presented and discussed in podium sessions. We assessed original data on surgical procedures published since 2008 with a minimum follow-up time of at least 12 months. If the studies included descriptions of perioperative complications, this minimum follow-up period did not apply.

Recommendations: The guideline encompasses recommendations for the diagnosis and treatment of female pelvic organ prolapse. Recommendations for anterior, posterior and apical pelvic organ prolapse with or without concomitant stress urinary incontinence, uterine preservation options, and the pros and cons of mesh placements during surgery for pelvic organ pro-

\section{Zusammenfassung \\ $\nabla$}

Ziel: Erstellung einer offiziellen, internationalen, interdisziplinären Leitlinie, publiziert und koordiniert von der Deutschen Gesellschaft für Gynäkologie und Geburtshilfe (DGGG). Die Leitlinie wurde für den deutschsprachigen Raum entwickelt und wird neben der DGGG auch von der Schweizerischen Gesellschaft für Gynäkologie und Geburtshilfe (SGGG) und der Österreichischen Gesellschaft für Gynäkologie und Geburtshilfe (OEGGG) mitgetragen. Das Ziel dieser Leitlinie, die von der DGGG publiziert und koordiniert wurde, ist es, durch die Evaluation der relevanten Literatur einen evidenzbasierten Überblick über die Diagnostik sowie konservative und operative Therapie des Descensus genitalis der Frau mit oder ohne Belastungsinkontinenz zu geben.

Methoden: Es erfolgte ein systematischer Review sowie Synthese von Daten, anteilig mit Metaanalyse (S2e). Es wurde eine umfassende Literatursuche in MEDLINE, Embase, Cinahl, Pedro und im Cochrane-Register, in Referenzlisten und in den Abstracts der Annual Meetings der International Continence Society und der International Urogynecological Association durchgeführt. Abstracts wurden eingeschlossen, wenn es sich um randomisierte Studien handelte, die als Podiumpräsentation vorgestellt und diskutiert wurden. Es wurden Originalarbeiten seit 2008 eingeschlossen, deren Nachkontrollzeitraum bei mindestens 12 Monaten lag. Für die Beschreibung von perioperativen Komplikationen wurden jegliche Daten herangezogen.

Empfehlungen: Es werden Empfehlungen zur Diagnostik, konservativen und operativen Therapie des Genitaldeszensus gegeben, wobei die 3 urogynäkologischen Kompartimente, Prävention oder Behandlung von Belastungsinkontinenz, Vor- und Nachteile von Netzaugmentationen sowie uteruserhaltende Optionen, berücksichtigt 
lapse are presented. The recommendations are based on an extensive and systematic review and evaluation of the current literature and include the experiences and specific conditions in Germany, Austria and Switzerland. wurden. Sie beruhen auf einer umfassenden, systematischen und aktuellen Literaturbetrachtung und -auswertung unter Berücksichtigung von Erfahrungen und spezifischen Bedingungen in Deutschland, Österreich und der Schweiz.

\section{Information on the Guideline}

Guidelines program of the DGGG, OEGGG and SGGG Information on the guidelines program is available at the end of the guideline.

\section{Citation format}

Diagnosis and therapy of female pelvic organ prolapse. Guideline of the DGGG, SGGG and OEGGG (S2e-Level, AWMF Registry Number 015/006, April 2016). Geburtsh Frauenheilk 2016; 76: $1287-1301$

\section{Table 1 Authors}

\begin{tabular}{|c|c|}
\hline \multicolumn{2}{|l|}{$\begin{array}{l}\text { Author } \\
\text { Mandate holder }\end{array}$} \\
\hline \multicolumn{2}{|c|}{ Coordinating lead guideline author: } \\
\hline PD Dr. med. Kaven Baeßler & $\begin{array}{l}\text { Deutsche Gesellschaft für Gynäkologie und Geburtshilfe e. V. (DGGG) [German Society for Gynecology and Obstetrics], } \\
\text { Arbeitsgemeinschaft für Urogynäkologie und Beckenbodenrekonstruktion (AGUB) [Study Group for Urogynecology and Pelvic } \\
\text { Floor Reconstruction] }\end{array}$ \\
\hline \multicolumn{2}{|l|}{ Other lead guideline authors: } \\
\hline $\begin{array}{l}\text { PD Dr. med. } \\
\text { Thomas Aigmüller }\end{array}$ & $\begin{array}{l}\text { Österreichische Gesellschaft für Gynäkologie und Geburtshilfe (OEGGG) [Austrian Society for Gynecology and Obstetrics], } \\
\text { Österreichische Arbeitsgemeinschaft für Urogynäkologie \& Rekonstruktive Beckenbodenchirurgie (AUB) [Austrian Study Group } \\
\text { for Urogynecology \& Reconstructive Pelvic Floor Surgery] }\end{array}$ \\
\hline PD Dr. med. Stefan Albrich & $\begin{array}{l}\text { Deutsche Gesellschaft für Gynäkologie und Geburtshilfe e. V. (DGGG), Arbeitsgemeinschaft für Urogynäkologie und Becken- } \\
\text { bodenrekonstruktion (AGUB), Berufsverband der Frauenärzte e. V. (BVF) [Professional Association of German Gynecologists] }\end{array}$ \\
\hline Prof. Dr. med. & Deutsche Gesellschaft für Gynäkologie und Geburtshilfe e. V. (DGGG), \\
\hline Christoph Anthuber & Arbeitsgemeinschaft für Urogynäkologie und Beckenbodenrekonstruktion (AGUB) \\
\hline PD Dr. med. Dominique Finas & $\begin{array}{l}\text { Deutsche Gesellschaft für Gynäkologie und Geburtshilfe e. V. (DGGG), } \\
\text { Arbeitsgemeinschaft für Urogynäkologie und Beckenbodenrekonstruktion (AGUB) }\end{array}$ \\
\hline Dr. med. Thomas Fink & $\begin{array}{l}\text { Deutsche Gesellschaft für Gynäkologie und Geburtshilfe e. V. (DGGG), } \\
\text { Arbeitsgemeinschaft für Urogynäkologie und Beckenbodenrekonstruktion (AGUB) }\end{array}$ \\
\hline Dr. med. Christian Fünfgeld & $\begin{array}{l}\text { Deutsche Gesellschaft für Gynäkologie und Geburtshilfe e. V. (DGGG), } \\
\text { Arbeitsgemeinschaft für Urogynäkologie und Beckenbodenrekonstruktion (AGUB) }\end{array}$ \\
\hline Prof. Dr. med. Boris Gabriel & $\begin{array}{l}\text { Deutsche Gesellschaft für Gynäkologie und Geburtshilfe e. V. (DGGG), } \\
\text { Arbeitsgemeinschaft für Urogynäkologie und Beckenbodenrekonstruktion (AGUB) }\end{array}$ \\
\hline Ulla Henscher & Deutscher Verband für Physiotherapie (ZVK) e. V. [Professional Association of Physiotherapists in Germany] \\
\hline Prof. Dr. med. Franc H. Hetzer & Deutsche Gesellschaft für Koloproktologie e. V. (DGK) [German Society for Coloproctology] \\
\hline PD Dr. med. Markus Hübner & $\begin{array}{l}\text { Deutsche Gesellschaft für Gynäkologie und Geburtshilfe e. V. (DGGG), } \\
\text { Arbeitsgemeinschaft für Urogynäkologie und Beckenbodenrekonstruktion (AGUB), Berufsverband der Frauenärzte e.V. (BVF) }\end{array}$ \\
\hline Bärbel Junginger, B. Sc. & Bundesverband selbstständiger Physiotherapeuten (IFK) e. V. [Professional Association of Independent Physiotherapists] \\
\hline PD Dr. med. Katharina Jundt & $\begin{array}{l}\text { Deutsche Gesellschaft für Gynäkologie und Geburtshilfe e. V. (DGGG), } \\
\text { Arbeitsgemeinschaft für Urogynäkologie und Beckenbodenrekonstruktion (AGUB), Berufsverband der Frauenärzte e. V. (BVF) }\end{array}$ \\
\hline Dr. med. Stephan Kropshofer & $\begin{array}{l}\text { Österreichische Gesellschaft für Gynäkologie und Geburtshilfe (OEGGG), } \\
\text { Österreichische Arbeitsgemeinschaft für Urogynäkologie \& Rekonstruktive Beckenbodenchirurgie (AUB) }\end{array}$ \\
\hline Prof. Dr. med. Annette Kuhn & $\begin{array}{l}\text { Schweizerische Gesellschaft für Gynäkologie und Geburtshilfe (SGGG) [Swiss Society for Gynecology and Obstetrics], Arbeitsge- } \\
\text { meinschaft für Urogynäkologie und Beckenboden-Pathologie (AUG) [Study Group for Urogynecology and Pelvic Floor Pathologies] }\end{array}$ \\
\hline Dr. med. Liane Logé & $\begin{array}{l}\text { Deutsche Gesellschaft für Gynäkologie und Geburtshilfe e. V. (DGGG), } \\
\text { Arbeitsgemeinschaft für Urogynäkologie und Beckenbodenrekonstruktion (AGUB) }\end{array}$ \\
\hline PD Dr. med. Gert Nauman & $\begin{array}{l}\text { Deutsche Gesellschaft für Gynäkologie und Geburtshilfe e. V. (DGGG), } \\
\text { Arbeitsgemeinschaft für Urogynäkologie und Beckenbodenrekonstruktion (AGUB) }\end{array}$ \\
\hline Prof. Dr. med. Ursula Peschers & $\begin{array}{l}\text { Deutsche Gesellschaft für Gynäkologie und Geburtshilfe e. V. (DGGG), } \\
\text { Arbeitsgemeinschaft für Urogynäkologie und Beckenbodenrekonstruktion (AGUB) }\end{array}$ \\
\hline Tatiana Pfiffer & $\begin{array}{l}\text { Deutsche Gesellschaft für Gynäkologie und Geburtshilfe e. V. (DGGG), } \\
\text { Arbeitsgemeinschaft für Urogynäkologie und Beckenbodenrekonstruktion (AGUB) }\end{array}$ \\
\hline $\begin{array}{l}\text { Prof. Dr. med. } \\
\text { Oliver Schwandner }\end{array}$ & $\begin{array}{l}\text { Chirurgische Arbeitsgemeinschaft für Coloproktologie (CACP) [Surgical Study Group for Coloproctology], } \\
\text { Deutsche Gesellschaft für Koloproktologie e. V. (DGK) }\end{array}$ \\
\hline $\begin{array}{l}\text { Prof. Dr. med. } \\
\text { Alexander Strauss }\end{array}$ & $\begin{array}{l}\text { Deutsche Gesellschaft für Gynäkologie und Geburtshilfe e. V. (DGGG), } \\
\text { Arbeitsqemeinschaft für Urogynäkologie und Beckenbodenrekonstruktion (AGUB) }\end{array}$ \\
\hline Prof. Dr. med. Ralf Tunn & $\begin{array}{l}\text { Deutsche Gesellschaft für Gynäkologie und Geburtshilfe e. V. (DGGG), } \\
\text { Arbeitsgemeinschaft für Urogynäkologie und Beckenbodenrekonstruktion (AGUB) }\end{array}$ \\
\hline Prof. Dr. med. Volker Viereck & $\begin{array}{l}\text { Schweizerische Gesellschaft für Gynäkologie und Geburtshilfe (SGGG), Arbeitsgemeinschaft für Urogynäkologie und Becken- } \\
\text { boden-Pathologie (AUG), Deutsche Gesellschaft für Gynäkologie und Geburtshilfe e. V. (DGGG), Arbeitsgemeinschaft für } \\
\text { Urogynäkologie und Beckenbodenrekonstruktion (AGUB) }\end{array}$ \\
\hline
\end{tabular}




\section{Guideline documents}

The complete long version together with a list of the conflicts of interest of all authors, a guideline report and a PDF slide version for PowerPoint presentations are available in German on the homepage of the AWMF:

http://www.awmf.org/leitlinien/detail/1l/015-006.html

\section{Authors}

\section{Cf. Table 1.}

$\begin{array}{ll}\text { Abbreviations } \\ \text { CI } & \text { Confidence interval } \\ \text { ICI } & \text { International Consultation on Incontinence } \\ \text { ICS } & \text { International Continence Society } \\ \text { IUGA } & \text { International Urogynecological Association } \\ \text { OAB } & \text { Overactive bladder } \\ \text { OR } & \text { Odds ratio } \\ \text { POPQ } & \text { Pelvic organ prolapse quantification system } \\ \text { QOL } & \text { Quality of life } \\ \text { RCT } & \text { Randomized controlled trial } \\ \text { RR } & \text { Relative risk } \\ \text { TVT } & \text { Tension-free vaginal tape }\end{array}$

\section{Application of the Guideline}

\section{Purpose and objectives}

The aim of this guideline is to provide an evidence-based overview of the diagnosis and the conservative and surgical therapy of female pelvic organ prolapse and to offer support for targeted decision-making as part of individual patient care.

The recommendations are based on an extensive, systematic review and evaluation of the current literature and also take the experiences and specific conditions in Germany, Austria and Switzerland into account. This represents an update of the guidelines of 2008 and also includes the warnings issued by the American Food and Drug Administration (FDA) in its recent notification of 2011 (http://www.fda.gov/medicaldevices/safety/alertsandnotices/publichealthnotifications/ucm061976.htm), which resulted in considerable changes to pelvic surgery and the placement of surgical meshes. But of course, this guideline does not absolve physicians from the necessity of keeping up-to-date with the most recent literature and does not replace decision-making with the patient.

\section{Targeted area of patient care}

- Inpatient care, German-speaking countries, cross-sectoral care

- Outpatient care, German-speaking countries, cross-sectoral care

This guideline targets patients aged 18 years and older with symptomatic or asymptomatic female pelvic organ prolapse with or without stress urinary incontinence.

\section{User group/target audience}

This guideline is aimed at gynecologists, coloproctologists and physiotherapists. It additionally provides information for urologists and GPs.

\section{Adoption and period of validity}

This guideline is valid from May 1st, 2016 through to April 30th, 2019. Because of its specific contents, this period of validity is only an estimation. If important changes in the evidence should occur, amendments to the guideline will be published by the AWMF after a methodological validation even before the period of validity has expired.

\section{Methodology}

The methodology used to compile this guideline was based on a stratified classification system. The rules are prescribed by the AWMF rulebook (version 1.0). Guidelines are differentiated into lowest level (S1), intermediate level (S2e or S2k) and highest level (S3).The lowest level is defined as a collection of recommendations for action compiled by a non-representative group of experts. In 2004 the S2 category was subdivided into 2 sublevels: systematic evidence-based (S2e) and structurally consensusbased (S2k). The highest level (S3) integrates both approaches.

\section{This guideline corresponds to level: S2e}

\section{Literature search, inclusion and exclusion criteria}

- An extensive literature search in MEDLINE, Embase, Cinahl, Pedro and the Cochrane Register, in reference lists and among the abstracts of the Annual Meetings of the International Continence Society (ICS) and the International Urogynecological Association (IUGA).

- Abstracts were included if they described randomized studies which had been presented to and discussed by a panel of experts.

- Following the 2nd FDA warning in July 2011 on the use of synthetic meshes in vaginal prolapse surgery (http://www.fda. gov/downloads/medicaldevices/safety/alertsandnotices/ ucm262760.pdf), the original plan to include literature up until 2011 was expanded. Publications up until 2014 were included.

- Search terms: pelvic organ prolapse, cystocele, rectocele, enterocele, uterine prolapse AND therapy, pessary, pelvic floor exercise, pelvic floor muscle training, surgery, repair, colporrhaphy, sacrocolpopexy, sacral colpopexy, mesh, stress urinary incontinence; ultrasound, ultrasonography, urodynamics; complications

- Inclusion criteria: original research published since 2008; follow-up of at least 12 months to evaluate success rates; no time limits for descriptions of perioperative complications.

- No limitations with respect to language.

- Definition of anatomical success following surgery: no prolapse beyond stage 1 according to the IUGA/ICS prolapse quantification system [1,2]. Stage 2 is considered an anatomical failure. This corresponds approximately to Baden-Walker Grade 2, i.e. "prolapse to the hymen", while Grade 1 ("prolapse half-way to the hymen") would still be assessed as a success or as normal, as long as the patient is asymptomatic [3].

\section{Grading of evidence using Oxford}

For the purposes of this guideline, evidence was classified (levels 1-5) in accordance with the classification system of the Oxford Centre for Evidence-based Medicine in its 2009 version.

While the quality of the evidence (strength of evidence) is intended as an indication of the robustness of the published data and therefore of the degree of certainty/uncertainty associated with the data, the level of recommendation expresses the result of weighing up desired vs. unwanted consequences of alternative approaches. For more information, please refer to the following homepage: http://www.cebm.net/o?=1025. 


\section{Recommendation grading}

The individual recommendations have been formulated in such a way that they indicate the level of requirement for each recommendation. There are three levels of requirement. The level of requirement depends on the ratio between the benefits and the disadvantages of alternative approaches. The terms "must/must not" indicate a strong recommendation (high level of requirement), "should/should not" indicate a simple recommendation (mid-level requirement), and "can" or "may"/“cannot" or "may not" signify an open recommendation (limited level of requirement); if the recommendation is contraindicated, the physician must make a decision after carefully weighing up the options. This also applies to strong recommendations.

\begin{tabular}{|lll|}
\hline Symbol & $\begin{array}{l}\text { Description of grade } \\
\text { of recommendation }\end{array}$ & Wording \\
\hline A & Strong recommendation, highly binding & must/must not \\
\hline B & Recommendation, relatively binding & should/should not \\
\hline 0 & Open recommendation, not binding & may/may not \\
\hline
\end{tabular}

\section{Conflicts of interest}

The conflict of interest statements of all guideline authors were entered in the AWMF form, and the tabular list is included in the long version of the guideline and in the guideline report (both in German).

\section{Guideline}

\section{Introduction and definitions}

Female pelvic organ prolapse or female genital prolapse is a common condition in women; the incidence of pelvic organ prolapse is increasing due to the overall rise in life expectancy. Therapy options consist of a number of conservative or surgical approaches. The aim of this guideline is to provide an evidencebased description of the diagnosis and the conservative and surgical therapy of female pelvic organ prolapse in women aged over 18 years. National and international socio-economic conditions were also taken into consideration.

The recommendations for the diagnosis and treatment of female pelvic organ prolapse are based on an extensive, systematic review and evaluation of the recent literature which also took account of the experiences and specific conditions in Germany, Austria and Switzerland. The guideline is an update of the guideline published in 2008 and has also included the warnings of the American Food and Drug Administration (FDA), including the last notification published in 2011 (http://www.fda.gov/medicaldevices/safety/alertsandnotices/publichealthnotifications/

ucm061976.htm) which led to substantive changes in prolapse surgeries using mesh implants. General dissatisfaction with the anatomical outcomes following standard prolapse surgery resulted in a significant increase in the use of various biological and synthetic implants (meshes). Following the second warning by the FDA, some of industrially produced mesh kits which were still available five years ago have since been withdrawn from the market (e.g. Prolift ${ }^{\circledR}$, Prosima $^{\circledR}$, Avaulta $^{\circledR}$, Perigee ${ }^{\circledR}$ in the USA, in the meantime also Elevate ${ }^{\circledR}$ ). The material properties (macropores $>75 \mu \mathrm{m}$ and lightweight $\leq 32 \mathrm{~g} / \mathrm{m}^{2}$ meshes, no multifilament absorbable or non-absorbable materials) of the new generation of meshes have been improved or amended, and the required apical fixation has now also been integrated.
Female pelvic organ prolapse is often associated with stress urinary incontinence. The symptoms of stress urinary incontinence have been defined as a leakage or loss of urine in response to physical activities such as coughing or lifting. If urine leakage during coughing only occurs after repositioning of the prolapse during clinical examination or after insertion of a pessary, it is referred to as occult stress incontinence. In addition to repair of the prolapse, the simultaneous protection or recreation of continence is a special aspect which is also discussed in this guideline.

\section{Diagnosis \\ 2.1 Medical history}

A standardized questionnaire should be used to record the patient's specific medical history of pelvic floor symptoms. It is recommended that validated questionnaires which also include an assessment of the patient's quality of life should be used to assess quality control and in all studies [1]. Validated pelvic floor questionnaires available in German include the questionnaire of the International Consultation on Incontinence (ICI; www.iciq.net), the German version of the King's Health Questionnaire [2], the German version of the "urinary incontinence-specific measure of quality of life" (I-QOL) [3] and the German Pelvic Floor Questionnaire (German version of the Australian Pelvic Floor Questionnaire) [4], for which a validated post-therapeutic follow-up module is also available [5].

\subsection{Clinical examination}

In addition to standard inspection of the external genitalia, assessment of the prolapse is done using a split speculum, and the evaluation must include coughing or pushing. The extent of prolapse must be documented separately for the anterior (bladder, anterior vaginal walls), middle (cervix or uterine stump) and posterior compartment. Quantification of the pelvic organ prolapse using the ICS/IUGA standard terminology is internationally recommended $[6,7]$. This should then be followed by a cough stress test carried out both without repositioning and after repositioning of the prolapse, e.g. with a speculum, pessary, swab or digitally, to detect clinical or occult stress urinary incontinence.

Further examination must consist of vaginal palpation of the pelvic floor and must include an assessment of pelvic floor contractility as well as rectal examination of patients with defecation disorders and fecal incontinence.

Quick urine tests (dipstick test) are not sufficiently sensitive for proper urine analysis; women with dysuria and a negative urine dipstick test should be assessed using a urine culture test with an antibiogram $[8,9]$.

\subsection{Imaging \\ 2.3.1 Sonography}

For an in-depth discussion, please refer to the detailed AWMF guideline on the use of ultrasonography in urogynecology (only available in German: Sonographie im Rahmen der urogynäkologischen Diagnostik, 015-055).

Assessment of residual urine with ultrasonography is part of the standard examination for prolapse and bladder voiding disorders. 


\section{Evidence-based recommendation 2.E1}

Level of evidence 3

Grade of recommendation 0

Renal sonography to exclude urinary retention is particularly recommended in patients with high-grade prolapse. The prevalence of hydronephrosis is reported to be $5-17 \%$, although this usually decreases following surgical treatment [52-55].

\section{Evidence-based recommendation 2.E2}

Level of evidence 3

Grade of recommendation 0

Pelvic floor sonography can be a useful diagnostic tool in addition to vaginal and rectal examination.

Biological meshes are not detectable sonographically [10]. The position, mobility, folding and even tearing of the proximal anchor fixation of synthetic meshes can be detected sonographically using a perineal, introital or endovaginal approach [10-13].

\section{Evidence-based recommendation 2.E3}

Level of evidence 3

Grade of recommendation 0

Perineal sonography can also be used as visual biofeedback to explain findings to patients and show how pelvic floor contractions affect the bladder neck, e.g. prior to coughing to reduce the prolapse [14-16].

\section{Evidence-based recommendation 2.E4}

Level of evidence 4 Grade of recommendation 0

Vaginal sonography can be used to shed light on a number of different aspects:

- For a depiction of the uterus and the adnexa prior to surgery

- To exclude uterine pathologies prior to carrying out uterus-preserving surgery

- To assess cervical length or the relationship between the uterine body and the cervix: cervical elongation after uterus-preserving surgery can result in persisting symptoms.

- To exclude extrauterine pelvic pathologies

\subsubsection{MRI}

As with defecography, dynamic MRI can be used to obtain images of all three compartments at rest, during pressing, and during contractions of the pelvic floor [17]. Dynamic MRI can be used to visualize complex and/or recurrent prolapse conditions [18, 19] and is particularly suitable to assess internal rectal prolapse/ intussusception and rectal emptying or stool retention [20-22].

\section{Evidence-based recommendation 2.E5}

Level of evidence 3

Grade of recommendation 0

Dynamic MRI can be useful to visualize complex conditions and symptoms.

\subsection{Urodynamic examination}

\section{Evidence-based recommendation 2.E6}

Level of evidence 3

Grade of recommendation 0

A systematic review of diagnostic tests showed that the patient's medical history and a clinical stress test are good predictors of stress urinary incontinence in urodynamic studies $[23,24]$. There are no data which confirm the necessity of carrying out urodynamic studies prior to planned prolapse surgery. Occult stress incontinence can also be detected by carrying out stress test with a sufficiently full bladder after prolapse repositioning.

\subsection{Cystourethroscopy}

\section{Evidence-based recommendation 2.E7}

Level of evidence 4

Grade of recommendation 0

If diffuse symptoms and findings such as bladder pain and hematuria are also present, particularly if the patient has had a previous operation, cystourethroscopy can help to exclude morphological causes such as bladder tumors or stones, urethral stenosis, intravesical mesh erosion, or chronic urothelial changes caused by interstitial cystitis [25-27].

\section{Evidence-based recommendation 2.E8}

Level of evidence 3

Grade of recommendation B

Cystourethroscopy is recommended at the end of prolapse surgery to exclude intraoperative bladder and urethral injury and to establish ureter function.

\section{$3 \quad$ Patient Information}

To enable patients to make an informed decision, the information given to patients should be well structured and should include, where possible, the physician's own data on the successes and complications of interventions. The discussion with the patient should include information about the patient's medical condition; observant, conservative and surgical treatment options along with their anatomical and functional success rates; the advantages and disadvantages of mesh implants; complications and their treatment options; the impact of therapy on the patient's sexuality, bladder and bowel functions, and further surgical interventions which could potentially be necessary (e.g. two-stage stress urinary incontinence surgery).

\section{Conservative Therapy}

As many women are not aware of their pelvic organ prolapse, surgery should only be carried out in symptomatic patients and in patients who are bothered by the prolapse [28]. Conservative options include pelvic floor rehabilitation, pessary therapy, clinical observation, reduction of known risk factors such as obesity, smoking and chronic constipation, digital support during defecation (pressure placed on the posterior vaginal wall or the perineum).

\section{Evidence-based recommendation 4.E1}

Level of evidence 3 Grade of recommendation C

As prolapse regression without therapy has also been reported [28, 29], observation alone should also be listed as an option during the discussion with the patient.

\section{Evidence-based recommendation 4.E2}

Level of evidence 2 Grade of recommendation B

Systemic hormone replacement therapy is not beneficial for pelvic floor function and should not be explicitly prescribed to treat prolapse or incontinence $[30,31]$.

\section{Evidence-based recommendation 4.E3}

Level of evidence 2 Grade of recommendation B

The application of topical estrogen in the vagina is an established treatment for vaginal dryness and irritation of the vagina (e.g., to treat symptoms of atrophic vaginitis) $[32,33]$ and is essential in pessary therapy to prevent local lesions, bleeding, and necrosis [34,35]. 


\subsection{Pelvic floor muscle training}

Several randomized studies have shown that targeted pelvic floor muscle training can reduce the symptoms of prolapse, lower the grade of prolapse, and prevent progression [36-41]. Studies have also demonstrated an improvement in associated stress urinary incontinence following pelvic floor muscle training $[37,39,42]$. It should be noted, however, that in these studies the correct pelvic floor contraction was determined by the physiotherapist by means of palpation. This was then followed by individual and targeted training of the pelvic floor musculature, which should not be equated with the unspecific pelvic floor exercises often done in Germany [43].

Five controlled randomized studies reported conflicting results in response to the question whether perioperative pelvic floor muscle training could improve functional outcome after prolapse and/or incontinence surgery [44-47]: two of the studies [44,46] reported improved incontinence and prolapse symptoms; however, three other studies $[45,47,48]$ found no difference in outcomes.

\subsection{Pessary therapy}

Pessaries can be successfully fitted in most women [49], with observational studies reporting success in around $50-100 \%$ of cases; however, successful continuation of pessary therapy is much lower, with a reported rate of 14-67\% [50-59]. In addition to prolapse symptoms, stress incontinence has been reported to improve in $23-45 \%$ of cases; studies have also reported improvements for overactive bladder, defecation disorders, sexual function and body image [52,60-63]. A prospective study found no significant differences in terms of symptom scores between the functional results for pessary therapy and those for surgical therapy [64].

Indications for pessary therapy can include patient preference for conservative treatment, temporary family planning when the patient intends to have more children, and an increased risk of perioperative complications due to co-morbidities [65].

\subsection{Recommendations for conservative therapy}

\section{Evidence-based recommendation 4.E4}

Level of evidence 1

Grade of recommendation B

Targeted pelvic floor muscle training (note: not gymnastical exercises) should at least be offered to patients who have lower stages of prolapse (Stages I and II) to reduce prolapse symptoms and concomitant stress urinary incontinence.

\section{Evidence-based recommendation 4.E5}

Level of evidence 3

Grade of recommendation 0

Accompanying perioperative pelvic floor rehabilitation may be considered; however, the results reported in studies differ considerably.

\section{Evidence-based recommendation 4.E6}

Level of evidence 2 Grade of recommendation B Pessary therapy is a good conservative option which should be offered to patients. It is still not clear which pessary is most suitable for which type of prolapse.

\subsection{Anterior colporrhapy or anterior vaginal wall repair}

\section{Evidence-based recommendation 5.E1}

Level of evidence 3

Grade of recommendation B

Simultaneous apical fixation appears to significantly reduce the risk of recurrence. The patient should be examined to determine whether concomitant anterior and middle compartment prolapse is present, as anterior vaginal wall repair could be performed concomitantly with apical fixation.

\section{Evidence-based recommendation 5.E2}

Level of evidence 3 Grade of recommendation 0

The risk of cystocele recurrence appears to be higher following anterior vaginal wall repair in patients with levator defects (avulsions). Anterior mesh placement can be considered in these patients [74].

Prolapse of the anterior vaginal wall is commonly associated with an apical defect, so that surgical repair of the middle compartment should be considered in these patients [66].

Success rates for anterior vaginal wall repair were reported in 22 randomized studies; they varied strongly and also depended on the additional surgical procedures carried out concomitantly. Because of the different surgical techniques used in the studies, the calculated cumulative success rate of $63 \%$ for more than 1000 women who underwent surgery should be interpreted with caution. If surgery is performed concomitantly to support the apical (middle) compartment, the risk of recurrence decreases significantly (OR: 0.68; 95\% CI: 0.54-0.85).

The risk of recurrence appears to increase almost twofold in patients with levator defects (avulsion of the pubococcygeus muscle from the pubic rami) [67-70].

\subsection{Surgery using synthetic or biological implants}

\section{Evidence-based recommendation 5.E3}

Level of evidence 1 a Grade of recommendation A

The use of synthetic meshes in the anterior compartment further reduces the anatomical and subjective risk of prolapse recurrence but has no positive impact on patients' quality-of-life. However, de novo dyspareunia and re-operation for mesh complications and urinary stress incontinence are more common compared to anterior vaginal wall repair. The decision making process has to include information on rates of re-operation, chronic pain syndrome and dyspareunia.

\section{Evidence-based recommendation 5.E4}

Level of evidence 3

Grade of recommendation 0

When placing a synthetic mesh in the anterior compartment, concomitant apical mesh fixation or surgery to stabilize the middle compartment can be considered.

\section{Evidence-based recommendation 5.E5}

Level of evidence $\mathbf{1 b}$ Grade of recommendation B

Because the success rates for biological implants are not higher than the success rates for anterior vaginal wall repair, biological implants should not be used.

\section{Evidence-based recommendation 5.E6}

Level of evidence 3 Grade of recommendation 0 Women with levator defects (avulsion of the pubococcygeus muscle from the lower pubic rami) generally appear to have an increased risk of recurrence, although the risk is lower following anterior synthetic mesh augmentation. Anterior synthetic mesh augmentation can or may therefore be considered in these patients. 
In studies with apical fixation or concomitant apical surgery [7179], anterior repair using a synthetic mesh (excluding Prolift ${ }^{\circledR}$ and Perigee ${ }^{\circledR}$ ) had a cumulative success rate of $93 \%$; the cumulative success rate of studies without apical fixation or without standard apical surgery [80-89] was $83 \%$. The cumulative rate of mesh erosion was $8 \%(137 / 1740)$; the cumulative rate for chronic pain and de novo dyspareunia was 7\% (59/846).

In a retrospective analysis, women with levator avulsion had a higher risk of cystocele recurrence even after placement of a synthetic mesh [90].

A meta-analysis of randomized studies showed that the risk of recurrence increased threefold when no synthetic mesh was placed (RR: 3.5; 95\% CI: 2.7-4.4). The success rate for anterior repair was $52 \%$, which increased to $86 \%$ ( $p<0.001$ ) with mesh augmentation. Overall, repeat surgery for mesh complications, stress urinary incontinence or recurrent prolapse was more common following synthetic mesh implantation (RR: 0.58; 95\% CI: $0.42-$ 0.81 ). Anterior repair reduced the risk of a repeat operation. After anterior repair, the risk of de novo dyspareunia, which occurs more frequently after transobturator synthetic mesh placement, was also lower (RR: 0.46; 95\% CI: 0.22-0.96). But this was not reflected in the validated sexual questionnaires (PISQ) which were used in some studies.

Meta-analysis of randomized studies showed that Pelvicol ${ }^{\circledR}$ augmentation did not offer better results than anterior repair (RR: 1.3; 95\% CI: 0.8-2.2). Only one RCT [91] reported superior results following Pelvicol ${ }^{\circledR}$ augmentation. This did not change, even when the results of all studies which used any type of biological implant were combined; the use of biological graft material did not appear to improve success rates (RR: 1.34; 95\% CI: $0.97-$ 1.86).

\subsection{Vaginal, abdominal or laparoscopic repair of paravaginal defects}

Because studies differed considerably and the concomitant procedures, which mainly affected the middle compartment and often included apical fixation, also varied significantly, the reported success rates of between 70 and 100\% (vaginal repair: between 90 and 100\%, cumulative success rate: 91\% [92-97]; abdominal repair: between 70 and 95\%, cumulative success rate: 94\% [92, 98-102]; laparoscopic repair: only one study, success rate: $80 \%$ [103]) should be interpreted with caution.

\subsection{Recommendations for the anterior compartment}

\section{Evidence-based recommendation 5.E7}

Level of evidence 3 Grade of recommendation B If anterior vaginal wall repair is carried out, concomitant apical fixation appears to significantly decrease the risk of recurrence. Patients should therefore be examined carefully to determine whether they may have both anterior and middle compartment prolapse which would then allow anterior vaginal wall repair to be combined with apical fixation.

\section{Evidence-based recommendation 5.E8}

Level of evidence 3 Grade of recommendation 0

The presence of a levator defect (avulsion) appears to increase the risk of cystocele recurrence following anterior vaginal wall repair, and anterior mesh placement can be considered in these patients [70].

\section{Evidence-based recommendation 5.E9}

Level of evidence 1a Grade of recommendation A

The use of synthetic mesh in the anterior compartment reduces the anatomical and subjective rates of prolapse recurrence but without having an additional impact on patients' quality of life. However, rates of de novo dyspareunia and repeat surgery for mesh complications and stress urinary incontinence are higher compared to rates for anterior vaginal wall repair, indicating that discussions with the patient must include information about repeat surgery, chronic pain syndrome, and dyspareunia.

\section{Evidence-based recommendation 5.E10}

Level of evidence 3 Grade of recommendation 0

When placing a synthetic mesh in the anterior compartment it is worth considering concomitant apical mesh fixation or surgery to stabilize the middle compartment.

\section{Evidence-based recommendation 5.E11}

Level of evidence $1 \mathrm{~b}$ Grade of recommendation B

Because the success rates for biological implants are not higher compared to the rates for anterior vaginal wall repair, biological implants are not necessary.

\section{Evidence-based recommendation 5.E12}

Level of evidence 3

Grade of recommendation 0

Women with levator defects (avulsion of the pubococcygeus muscle from the pubic rami) generally appear to have a higher risk of recurrence, although the risk is lower after anterior synthetic mesh augmentation, which is why this approach should be considered for these patients.

\section{Evidence-based recommendation 5.E13}

Level of evidence 3 Grade of recommendation 0

A lack of adequate studies makes it impossible to give a clear recommendation in support of paravaginal defect repair, irrespective of whether it is carried out vaginally, abdominally or laparoscopically. This is because apical procedures are usually carried out concomitantly and contribute to high success rates.

\section{Surgical Therapy of Posterior Compartment Prolapse}

Rectoceles and posterior enteroceles can be the cause of both prolapse symptoms and defecation disorders. Defecation disorders often require manual transvaginal, transanal or perineal assistance. It is important to determine preoperatively whether these disorders are caused by a rectocele, an intussusception or by descending perineum syndrome. Interdisciplinary collaboration with coloproctologists can be useful, particularly if a defecation disorder is present without a visible rectocele.

\subsection{Posterior colporrhapy or posterior vaginal wall repair}

The cumulative success rate for posterior vaginal wall repair using midline suturing of vaginal connective tissue (fascia) is significantly higher at $86 \%$ (cumulative success rate: $83 / 576$ ) than the $70 \%$ reported for defect-specific repair (cumulative success rate: $82 / 271)$. The risk of recurrence is significantly reduced if midline fascial suturing is done (OR: $0.4 ; 95 \% \mathrm{CI}: 0.28-0.56)$, which is why this technique should be the method of choice for primary rectocele repair.

The standard approach used to consist of the plication of the levator ani, particularly of the distal levator, but this technique did not reduce the rate of recurrence (45/220, cumulative success rate $80 \%$ ). Instead, use of an isolated midline fascial suture has been found to yield better results (OR: 0.65; 95\% CI: 0.44-0.98) [104-106]. Approximation of the levator ani is not considered 
necessary for posterior vaginal wall repair, as the success rates with this method are not higher than those obtained using a midline fascial suture, and high rates of dyspareunia have been reported with this technique.

Two randomized studies reported that transvaginal posterior vaginal wall repair was superior to transanal rectocele repair in terms of anatomical and functional success rates [104,107]. Transvaginal posterior vaginal wall repair is the method of choice to treat symptomatic rectocele and should be used in preference to transanal rectocele repair.

\subsection{Surgery using synthetic or biological implants}

The use of biological implants in the posterior compartment did not show any benefits compared to posterior vaginal wall repair. On the contrary, posterior vaginal wall repair was found to be superior to the augmentation procedure with grafts, and metaanalysis of all comparative randomized and non-randomized studies showed that posterior vaginal wall repair halved the risk of recurrence (RR: $0.58 ; 95 \% \mathrm{CI}: 0.41-0.84$ ). The use of xenografts (biological implants) in the posterior compartment should be avoided because their use offers no benefits.

There are no randomized studies on the use of non-absorbable synthetic mesh in the posterior compartment. Although noncontrolled prospective and retrospective studies reported a lower rate of recurrence when synthetic mesh was used, there are currently no comparative studies. There is therefore no reason to use synthetic meshes routinely for primary vaginal wall repair of the posterior compartment.

\subsection{Recommendations for the posterior compartment}

\section{Evidence-based recommendation 6.E1}

Level of evidence 1

Grade of recommendation A

Posterior vaginal wall repair to treat a symptomatic rectocele should be

chosen in preference to transanal rectocele repair.

\section{Evidence-based recommendation 6.E2}

Level of evidence 2

Grade of recommendation B

Posterior vaginal wall repair using midline fascial suturing resulted in higher rates of success compared to defect-specific fascial repair and this method should be preferred for primary rectocele repair.

\section{Evidence-based recommendation 6.E3}

Level of evidence 3

Grade of recommendation 0

Plication of the levator ani is not necessary for posterior vaginal wall repair as it does not result in higher success rates compared to a midline fascial repair and the procedure is associated with high rates of dyspareunia.

\section{Evidence-based recommendation 6.E4}

Level of evidence $\mathbf{1 b}$ Grade of recommendation A Xenografts (biological implants) should not be used for prolapse repair in the posterior compartment because their use offers no benefits.

\section{Evidence-based recommendation 6.E5}

Level of evidence 3 Grade of recommendation 0 There are no randomized studies on the use of non-absorbable mesh in the posterior compartment. Although non-controlled prospective and retrospective studies showed that synthetic mesh placement was associated with a lower rate of recurrence, there are no comparative studies on this issue. There is therefore currently no reason to use synthetic meshes routinely for primary repair of the posterior compartment.

\section{Surgical Therapy of Middle Compartment Prolapse}

The surgical repair of suspension defects in the middle compartment (level 1 according to DeLancey [108]) is of special importance as this repair is often carried out in addition to repair of the anterior or posterior compartment and is also as a standalone procedure to treat uterine or vaginal vault prolapse.

\subsection{Uterosacral ligament fixation/McCall technique/ Shull technique}

A systematic review of transvaginal high fixation of the vaginal vault to the uterosacral ligaments showed a cumulative apical success rate of $98 \%$ (95\% CI: 95.7-100), an anterior success rate of $81 \%$ (95\% CI: $67.5-94.9$ ) and a posterior success rate of $87 \%$ (95\% CI: 80-94.9) [109]. Retrospective studies of laparoscopic fixation of the vaginal vault to the uterosacral ligaments after concomitant hysterectomy reported an apical failure rate of 11$13 \%[110,111]$.

Vaginal suspension using the uterosacral ligaments is associated with the risk of ureteral injury, ureter ligation and ureteral medial deviation in around $6 \%(1-11 \%)$, and intraoperative cystoscopy is therefore recommended.

\subsection{Sacrospinous fixation}

In a randomized study published in 2014, Barber et al. [48] reported no significant anatomical or functional differences between vaginal fixation to the uterosacral ligaments or sacrospinous fixation.

Recurrence is most common in the anterior compartment, with reported rates of $5-39 \%(157 / 1036,15 \%)$, and occurs less often in the posterior compartment (5-12\%, 32/442, 7\%). Apical fixation is very effective with a cumulative success rate of $96 \%$ (rate of recurrence: $0-14 \%, 45 / 1121$ [4\%]).

\subsection{Abdominal, laparoscopic and robot-assisted sacrocolpopexy}

A systematic review by Nygaard et al. [112] reported apical success rates of $78-100 \%$ for abdominal sacrocolpopexy and a cumulative rate of re-operation for prolapse recurrence of $4.4 \%$. In 23 studies, laparoscopic sacrocolpopexy had an equally high cumulative success rate of $91 \%$ (number of failures: 215/2341).

In a randomized study, Maher et al. compared laparoscopic sacrocolpopexy including anterior and posterior polypropylene mesh extension with the vaginal Prolift ${ }^{\circledR}$ mesh kit which has since been withdrawn from the market by its manufacturer (Ethi$\operatorname{con}^{\circledR}$ ) and is no longer available [113]. While laparoscopic sacrocolpopexy took longer (difference: + 52 min [95\% CI: 41.5-62.6]), patients were discharged earlier from hospital and were able to resume day-to-day activities more quickly. After two years, recurrence across all compartments was significantly more common in the vaginal mesh group (57 vs. $23 \%$ ) [113], as was the rate of re-operations ( 22 vs. $5 \%, \mathrm{p}=0.006$ ).

\subsection{Vaginal high levator myorrhaphy and vaginal fixation of the vaginal vault to the lliococcygeus fascia}

In a randomized study, the apical success rate was $97 \%$ after levator myorrhaphy and $98 \%$ following uterosacral ligament fixation. The rate of cystocele recurrence was relatively high at 29 and $35 \%$, respectively [114]. There are only a few case series describing vaginal fixation to the fascia of the iliococcygeus muscle, with apical success rates of 53,83 and $96 \%$. 


\subsection{Uterus-preserving procedures}

If the uterus is healthy with no history of previous disease and no signs of clinical or sonographic uterine pathology, if the patient wishes it, she should be offered a uterus-preserving procedure. Options include vaginal sacrospinous hysteropexy, laparoscopic or open sacrohysteropexy with mesh interposition, and fixation of the uterus to the uterosacral ligaments. Please also refer to the AWMF hysterectomy guideline (015-070).

Five studies directly compared vaginal hysterectomy with vaginal vault fixation to the uterosacral ligaments and sacrospinous hysteropexy but found no significant differences (rates of recurrence: 8 vs. $4 \%$ ).

\subsection{Colpocleisis}

Colpocleisis is considered a relatively quick procedure with few complications and is predominantly offered to older women with multiple morbidities who are no longer sexually active and no longer wish to be sexually active. Recurrence following colpocleisis is very rare; studies report an improvement in quality of life and in bladder and bowel function but also that a small number of women $(<5 \%)$ regretted the operation $[115,116]$. Crisp et al. [117] reported in 2013 that $13.8 \%$ of 87 women regretted the procedure.

\subsection{Recommendations for the middle compartment}

\section{Evidence-based recommendation 7.E1}

Level of evidence 2

Grade of recommendation A

There is good evidence showing that sacrospinous colpopexy, vaginal or laparoscopic fixation to the uterosacral ligaments and open, laparoscopic or robot-assisted sacrocolpopexy can all be used for the repair of middle compartment prolapse, with success rates of more than $90 \%$ reported in the literature. The final choice of procedure must be made together with the patient and must weigh up all the findings and symptoms, comorbidities, risk factors, the potential benefit of a planned concomitant hysterectomy procedure, the patient's own wishes, and the department's level of expertise.

\section{Evidence-based recommendation 7.E2}

Level of evidence 2

Grade of recommendation B

Abdominal sacrocolpopexy is a procedure which has been studied very extensively and for the longest period of time; it is currently the most effective procedure. Laparoscopic sacrocolpopexy can also be considered by departments with the necessary experience in carrying out the procedure.

\section{Evidence-based recommendation 7.E3}

Level of evidence 2

Grade of recommendation B

Carrying out a hysterectomy concomitantly with sacrocolpopexy should be avoided because of the increased risk of mesh erosion.

\section{Evidence-based recommendation 7.E4}

Level of evidence $1 \mathrm{~b}$ Grade of recommendation B Sacrocolpopexy and sacrospinous fixation procedures are approximately equivalent but offer different benefits and have different disadvantages. If there are no contraindications, sacrocolpopexy can be carried out in preference to sacrospinous fixation.

\section{Evidence-based recommendation 7.E5}

Level of evidence 2

Grade of recommendation A

The use of absorbable or biological implants for fixation to the sacrum in sacrocolpopexy is not recommended.

\section{Evidence-based recommendation 7.E6}

Level of evidence 2

Grade of recommendation B

Intraoperative cystoscopy is recommended for vaginal vault suspension to the uterosacral ligaments because of the increased risk of injury to the ureter.

\section{Evidence-based recommendation 7.E7}

Level of evidence 2

Grade of recommendation B

Uterine preservation should be considered in patients with the appropriate indications. Vaginal sacrospinous hysteropexy is a good option; there is not yet enough long-term data available on sacrohysteropexy procedures with mesh interposition or fixation to the uterosacral ligaments.

\section{Evidence-based recommendation 7.E8}

Level of evidence 3 Grade of recommendation 0

Vaginal high levator myorrhaphy and vaginal fixation of the vaginal vault to the fascia of the iliococcygeus muscle have not been studied much and should therefore only be carried out if specifically indicated or if there are no other alternatives.

\section{Evidence-based recommendation 7.E9}

Level of evidence 3 Grade of recommendation 0

Colpocleisis can be considered in selected patients after carefully discussing the procedure with patients.

8 Genital prolapse and stress urinary incontinence A risk calculator to weigh up the risk of postoperative stress incontinence was developed based on several models and studies [118]. The risk calculator takes a number of factors into account (www.r-calc.com/ExistingFormulas.aspx?filter=CCQHS).

\subsection{Continent women with genital prolapse}

A meta-analysis showed that, compared to transobturator mesh procedures, anterior vaginal wall repair protected patients from developing stress incontinence (RR: 0.64; 95\% CI: 0.42-0.97) [119]. However, one study evaluated the long-term data after three years and no longer found any significant difference between the two procedures $[72,120]$.

The CARE study [121] compared abdominal sacrocolpopexy in preoperatively continent women with $(n=157)$ and without ( $n=165)$ concomitant Burch colposuspension. At two years postoperatively, significantly fewer women in the Burch group were incontinent. The study was therefore terminated ahead of schedule and is underpowered.

\subsection{Women with symptomatic stress urinary incontinence and genital prolapse}

The results of two randomized studies of women with stress incontinence and cystocele who underwent anterior vaginal wall repair showed that $48 \%$ (19/40) were continent postoperatively $[122,123]$. The cumulative continence rate following transobturator mesh was $61 \%(81 / 132)$ [124-126]. However, after the additional insertion of a suburethral tape, 235 out of 237 women (99\%) were continent postoperatively [87, 127-129].

One randomized study investigated the question whether treatment should be carried out as a one-stage or a two-stage procedure; it was found that the treatment of stress incontinence was equally successful, irrespective of whether the suburethral TVT was inserted at the same time as the anterior vaginal wall repair $(83 / 87,95 \%)$ or three months later $(47 / 53,89 \%$; based on an ontreatment analysis) [130]. However, 27/94 women (29\%) were continent following prolapse surgery alone and refused the planned TVT procedure three months later [130]. 


\subsection{Women with occult stress incontinence and genital prolapse}

Three randomized studies reported that suburethral tape insertion concomitantly with prolapse repair (especially anterior vaginal wall repair) significantly reduced stress incontinence rates (21/116, $18 \%$ vs. $64 / 125,51 \%)$ [131-133]. A meta-analysis of these studies showed a decrease by almost 50\% (RR: 0.54; $95 \%$ CI: 0.41-0.72).

\subsection{Recommendations for prolapse and urinary stress incontinence}

\section{Evidence-based recommendation 8.E}

Level of evidence 2

Grade of recommendation B

In preoperatively continent women with genital prolapse, anterior vaginal wall repair is preferable to transobturator mesh placement to reduce the rate of de novo stress incontinence. The higher rate of recurrence associated with anterior vaginal wall repair compared to transobturator mesh placement should be take into consideration when discussing potential procedures with the patient.

\section{Evidence-based recommendation 8.E2}

Level of evidence 2

Grade of recommendation B

A concomitant Burch colposuspension can be additionally offered to patients undergoing sacrocolpopexy as a prophylactic measure against postoperative stress incontinence.

\section{Evidence-based recommendation 8.E3}

Level of evidence 1 a

Grade of recommendation A

Patients with occult stress incontinence should be informed about the possibility of undergoing concomitant suburethral tape insertion during vaginal prolapse surgery.

\section{Evidence-based recommendation 8.E4}

Level of evidence 2

Grade of recommendation A

Suburethral tape insertion can also be performed as a two-stage procedure, e.g. at three months after prolapse surgery.

\section{Evidence-based recommendation 8.E5}

Level of evidence 2

Grade of recommendation B

Women with symptomatic stress incontinence and prolapse can be offered simultaneous surgery to treat stress incontinence.

\section{Evidence-based recommendation 8.E6}

Level of evidence 2 Grade of recommendation 0

Suburethral tape insertion can be carried out in preference to Burch colposuspension when treating patients with sacrocolpopexy.

\section{$9 \quad$ Perioperative Management}

There is very little evidence-based literature on the perioperative management of gynecological or urogynecological patients. Please refer to the appropriate AWMF guidelines for the perioperative administration of antibiotics, thrombosis prophylaxis and patient positioning (029-022, 003-001, 015-077).

\section{Evidence-based recommendation 9.E1}

Level of evidence 2

Grade of recommendation 0

Preoperative and/or postoperative pelvic floor muscle training may be prescribed; however, there is no clear evidence that this will improve incontinence and prolapse compared to pelvic floor surgery without perioperative pelvic floor muscle training.

\section{Evidence-based recommendation 9.E2}

Level of evidence 2 Grade of recommendation B

The preoperative placement of ureteral stents can be dispensed with as it does not reduce ureteral injuries.

\section{Evidence-based recommendation 9.E3}

Level of evidence 3

Grade of recommendation 0

Postoperative application of topical estrogen can improve vaginal flora and reduce granulation tissue; there is no evidence that it reduces the rates of mesh erosion.

\section{Complications and Their Treatment}

\subsection{Mesh erosion, extrusion, shrinkage}

The rates of vaginal erosion following abdominal sacrocolpopexy are between 0 and $10 \%$ after 7 years [134]. The reported rates following vaginal mesh implantation were between 0 and $30 \%$ [135, 136]; in the analysis carried out for this guideline the calculated rate was $8 \%(137 / 1740)$. Risk factors for erosion were concomitant hysterectomy procedure, smoking, and the use of polytetrafluoroethylene mesh [134] as well as higher BMI $>30 \mathrm{~kg} / \mathrm{m}^{2}$ (OR: 10) [137]. The colpotomy required for mesh placement should be as short as possible [138]. Smoking increases the risk of vaginal mesh erosion in both vaginal and abdominal mesh implantations (OR: 4.2; 95\% CI: 2.5-7.0) [139142].

Treatment depends on the extent of erosion and the presence or absence of co-infections. Topical application of estrogen is recommended but is often not enough, and partial excision of the mesh is then necessary [143]. The cumulative success rate for topical estrogen application to treat vaginal erosion is $24 \%$ (33/ 139) $[142,144-149]$.

\subsection{Organ injuries}

There are few reports in the literature on injuries to the bladder, urethra and ureter. Late visceral mesh erosion is rare, and the only literature to date consists of individual case reports.

Mesh implantation is still possible after intraoperative bladder injury and repair immediately intraoperatively. However, placement of a synthetic mesh should be avoided if there is inadvertent rectotomy intraoperatively.

\subsection{Sexual dysfunction}

Prolapse surgery can improve dyspareunia but it can also be the cause of dyspareunia arising from scarring, overcorrection, hematoma formation, or nerve irritation or injury. Chronic pain and dyspareunia have been reported in $3-13 \%$ of cases, particularly after vaginal mesh placement $[135,136]$. If the cause of discomfort is found to be "tension" of the mesh or its fixation arms, treatment options include mobilization of the mesh, incision of the mesh or of its fixation arms, and excision of part of the mesh $[144,150]$. Complete excision of the mesh is rarely indicated. Surgical procedures to partially or completely excise the mesh can be difficult; surgery may not always eliminate or reduce patient discomfort and can lead to further complications [150-152]. This is a particular problem of mesh-assisted surgical procedures, and it is therefore particularly important to provide the patient with detailed information on the risks involved. 


\subsection{Recommendations for the management of complications}

\section{Evidence-based recommendation 10.E1}

Level of evidence 3

Grade of recommendation B

During the discussion with their physician, patients who smoke should be informed about the increased risk of mesh erosion after planned mesh implantation, and the physician should recommend that the patient stops smoking.

\section{Evidence-based recommendation 10.E2}

Level of evidence 3

Grade of recommendation B

Initial treatment of vaginal mesh erosion can consist of the application of topical estriol or estradiol. If the patient does not respond to treatment, local excision of the exposed mesh should be performed using tension-free vaginal suturing.

\section{Evidence-based recommendation 10.E3}

Level of evidence 3

Grade of recommendation B

Complete excision of the mesh, particularly of multifilament mesh, should be aimed for in patients with chronic mesh infection or recurrent abscess.

\section{Evidence-based recommendation 10.E4}

Level of evidence 3

Grade of recommendation B

Because of the high number of associated complications, multifilament mesh should not be used for prolapse repair.

\section{Evidence-based recommendation 10.E5}

Level of evidence 3 Grade of recommendation 0

If the mesh arms or the synthetic mesh are identified as the cause of chronic pain syndrome, partial or complete mesh excision or division of fixation arms from the central graft can be considered.

\section{Evidence-based recommendation 10.E6}

\section{Level of evidence 4}

Grade of recommendation 0

Planned mesh placement is still possible despite inadvertent injury to the bladder if the bladder is treated immediately intraoperatively; however, mesh placement should be avoided after inadvertent injury to the rectum.

\section{Summary}

An in-depth discussion with the patient about expectant, conservative and surgical management options to treat prolapse is necessary. Conservative options include targeted pelvic floor muscle training for patients with low grade prolapse, as this can reduce the extent of prolapse and incontinence symptoms, and pessary therapy. A pessary can usually be successfully fitted in most patients and is a low-risk option.

The individual surgical procedure should be chosen in a shared decision making process together with the patient. Current studies and evidence show that there is a wide range of surgical procedures which involve either autologous tissue or synthetic mesh augmentation. Because of the higher rate of complications after vaginal mesh implants, this should only be used when specifically indicated, after the patient has been informed in detail and the benefits and disadvantages carefully weighed up. At present, it is not possible to clearly define the indications. Possible indications include recurrent or total prolapse combined with risk factors such as obesity, chronic obstructive pulmonary disease and indications of generalized connective tissue weakness. Patients with levator defects (levator avulsions) have a higher risk of anterior compartment prolapse recurrence, and placement of a synthetic mesh appears to reduce this risk. Mesh placement should be considered for patients with high grade prolapse, prolapse re- currence, levator avulsions and for patients who are anxious about anatomical correction.

The patient must be informed in detail about the success rates of individual procedures with and without mesh placement, about the treatment alternatives and possible complications. The patient should be informed about the lack of studies on long-term outcomes after vaginal mesh placement.

Regular postoperative documentation of pelvic floor dysfunction and of patients' quality of life is recommended to evaluate the surgical technique and the indications and adapt them where necessary. New surgical procedures with or without implants should only be introduced in the context of clinical trials. In addition to anatomical outcomes, studies should particularly focus on the prospective evaluation of pelvic floor function and on patients' quality of life.

\section{Affiliations}

1 Beckenbodenzentrum, Charité Universitätsmedizin, Berlin, Germany

2 Universitätsklinik für Gynäkologie und Geburtshilfe, Med Uni Graz, Austria

3 Praxis “Frauenärzte Fünf Höfe” München, München, Germany

${ }^{4}$ Klinikum Starnberg, Starnberg, Germany

${ }^{5}$ Evangelisches Krankenhaus Bielefeld EvKB, Bielefeld, Germany

${ }^{6}$ Sana Klinikum Berlin Lichtenberg, Berlin, Germany

7 Klinik Tettnang, Tettnang, Germany

8 St. Josef's Hospital Wiesbaden, Wiesbaden, Germany

${ }^{9}$ Praxis für Physiotherapie, Hannover, Germany

10 Spital Linth, Uznach, Switzerland

11 Universitätsfrauenklinik Tübingen, Tübingen, Germany

12 Frauenarztpraxis am Pasinger Bahnhof, München, Germany

13 Tirolkliniken, Innsbruck, Austria

14 Inselspital Bern, Bern, Switzerland

15 Sana Klinikum Hof GmbH, Hof, Germany

16 Helios Klinikum Erfurt, Erfurt, Germany

17 Fachkliniken München AG, München, Germany

18 Asklepios Klinik Hamburg Harburg, Hamburg, Germany

${ }^{19}$ Krankenhaus Barmherzige Brüder, Regensburg, Germany

${ }^{20}$ Christian-Albrechts-Universität zu Kiel, Kiel, Germany

21 St. Hedwig Krankenhaus, Berlin, Germany

22 Kantonsspital Frauenfeld, Frauenfeld, Switzerland

\section{References}

1 Avery KN, Bosch JL, Gotoh $M$ et al. Questionnaires to assess urinary and anal incontinence: review and recommendations. J Urol 2007; 177: 39-49

2 Bjelic-Radisic V, Dorfer M, Tamussino K et al. Psychometric properties and validation of the German-language King's Health Questionnaire in women with stress urinary incontinence. Neurourol Urodyn 2005; 24: 63-68

3 Patrick DL, Martin ML, Bushnell DM et al. Cultural adaptation of a quality-of-life measure for urinary incontinence. Eur Urol 1999; 36: 427435

4 Baessler K, Kempkensteffen C. [Validation of a comprehensive pelvic floor questionnaire for the hospital, private practice and research]. Gynakol Geburtshilfliche Rundsch 2009; 49: 299-307

5 Baessler K, Junginger B. [Validation of a pelvic floor questionnaire with improvement and satisfaction scales to assess symptom severity, bothersomeness and quality of life before and after pelvic floor therapy]. Aktuelle Urol 2011; 42: 316-322

6 Bump RC, Mattiasson A, Bo K et al. The standardization of terminology of female pelvic organ prolapse and pelvic floor dysfunction. Am J Obstet Gynecol 1996; 175: 10-17

7 Haylen BT, de Ridder D, Freeman RM et al. An International Urogynecological Association (IUGA)/International Continence Society (ICS) joint report on the terminology for female pelvic floor dysfunction. Int Urogynecol J 2010; 21: 5-26

8 Eigbefoh JO, Isabu P, Okpere E et al. The diagnostic accuracy of the rapid dipstick test to predict asymptomatic urinary tract infection of pregnancy. J Obstet Gynaecol 2008; 28: 490-495

9 Hessdoerfer E, Jundt $K$, Peschers $U$. Is a dipstick test sufficient to exclude urinary tract infection in women with overactive bladder? Int Urogynecol J 2011; 22: 229-232

10 Dietz HP. Mesh in prolapse surgery: an imaging perspective. Ultrasound Obstet Gynecol 2012; 40: 495-503 
11 Svabik K, Martan A, Masata J et al. Ultrasound appearances after mesh implantation-evidence of mesh contraction or folding? Int Urogynecol J 2011; 22: 529-533

12 Shek KL, Dietz HP, Rane A et al. Transobturator mesh for cystocele repair: a short- to medium-term follow-up using 3D/4D ultrasound. Ultrasound Obstet Gynecol 2008; 32: 82-86

13 Tunn R, Picot A, Marschke J et al. Sonomorphological evaluation of polypropylene mesh implants after vaginal mesh repair in women with cystocele or rectocele. Ultrasound Obstet Gynecol 2007; 29: 449-452

14 Junginger B, Seibt E, Baessler K. Bladder-neck effective, integrative pelvic floor rehabilitation program: follow-up investigation. Eur J Obstet Gynecol Reprod Biol 2014; 174: 150-153

15 Dietz HP, Wilson PD, Clarke B. The use of perineal ultrasound to quantify levator activity and teach pelvic floor muscle exercises. Int Urogynecol J Pelvic Floor Dysfunct 2001; 12: 166-168; discussion 8-9

16 Thompson JA, O'Sullivan PB, Briffa NK et al. Assessment of voluntary pelvic floor muscle contraction in continent and incontinent women using transperineal ultrasound, manual muscle testing and vaginal squeeze pressure measurements. Int Urogynecol J Pelvic Floor Dysfunct 2006; 17: 624-630

17 Lienemann A, Anthuber C, Baron A et al. Dynamic MR colpocystorectography assessing pelvic-floor descent. Eur Radiol 1997; 7: 1309-1317

18 Lienemann A, Sprenger D, Anthuber $C$ et al. Functional cine magnetic resonance imaging in women after abdominal sacrocolpopexy. Obstet Gynecol 2001; 97: 81-85

19 Pannu HK, Kaufman HS, Cundiff GW et al. Dynamic MR imaging of pelvic organ prolapse: spectrum of abnormalities. Radiographics 2000; 20: 1567-1582

20 Bharucha AE, Fletcher JG, Harper CM et al. Relationship between symptoms and disordered continence mechanisms in women with idiopathic faecal incontinence. Gut 2005; 54: 546-555

21 Healy JC, Halligan S, Reznek RH et al. Patterns of prolapse in women with symptoms of pelvic floor weakness: assessment with MR imaging. Radiology 1997; 203: 77-81

22 Hetzer FH, Andreisek G, Tsagari C et al. MR defecography in patients with fecal incontinence: imaging findings and their effect on surgical management. Radiology 2006; 240: 449-457

23 Martin JL, Williams KS, Sutton AJ et al. Systematic review and metaanalysis of methods of diagnostic assessment for urinary incontinence. Neurourol Urodyn 2006; 25: 674-683; discussion 684

24 Digesu GA, Khullar V, Cardozo L et al. Overactive bladder symptoms: do we need urodynamics? Neurourol Urodyn 2003; 22: 105-108

25 Wai CY, Atnip SD, Williams KN et al. Urethral erosion of tension-free vaginal tape presenting as recurrent stress urinary incontinence. Int Urogynecol J Pelvic Floor Dysfunct 2004; 15: 353-355

26 Washington JL. Staple erosion into the bladder after mesh and staple laparoscopic colposuspension. A case report. J Reprod Med 2002; 47: 325-326

27 Vakili B, Chesson RR, Kyle BL et al. The incidence of urinary tract injury during hysterectomy: a prospective analysis based on universal cystoscopy. Am J Obstet Gynecol 2005; 192: 1599-1604

28 Baessler K, O'Neill S, Maher C. Prevalence, incidence, progression and regression of pelvic organ prolapse in a community cohort: Results of a 5-year longitudinal study. Neurourol Urodynam 2006; 25: 520-522

29 Handa VL, Garrett E, Hendrix S et al. Progression and remission of pelvic organ prolapse: a longitudinal study of menopausal women. Am J Obstet Gynecol 2004; 190: 27-32

30 Hendrix SL, Cochrane BB, Nygaard IE et al. Effects of estrogen with and without progestin on urinary incontinence. JAMA 2005; 293: 935-948

31 Ismail SI, Bain C, Hagen S. Oestrogens for treatment or prevention of pelvic organ prolapse in postmenopausal women. Cochrane Database Syst Rev 2010; (9): CD007063

32 Cardozo L, Lose G, McClish D et al. A systematic review of the effects of estrogens for symptoms suggestive of overactive bladder. Acta Obstet Gynecol Scand 2004; 83: 892-897

33 Bidmead J, Cardozo L, McLellan A et al. A comparison of the objective and subjective outcomes of colposuspension for stress incontinence in women. BJOG 2001; 108: 408-413

34 Cardozo L, Bachmann G, McClish D et al. Meta-analysis of estrogen therapy in the management of urogenital atrophy in postmenopausal women: second report of the Hormones and Urogenital Therapy Committee. Obstet Gynecol 1998; 92 (4 Pt 2): 722-727

35 Hanson LA, Schulz JA, Flood CG et al. Vaginal pessaries in managing women with pelvic organ prolapse and urinary incontinence: patient characteristics and factors contributing to success. Int Urogynecol J Pelvic Floor Dysfunct 2006; 17: 155-159

36 Kashyap R, Jain $V$, Singh A. Comparative effect of 2 packages of pelvic floor muscle training on the clinical course of stage I-III pelvic organ prolapse. Int J Gynaecol Obstet 2013; 121: 69-73

37 Stupp L, Resende AP, Oliveira E et al. Pelvic floor muscle training for treatment of pelvic organ prolapse: an assessor-blinded randomized controlled trial. Int Urogynecol J 2011; 22: 1233-1239

38 Hagen S, Stark D, Glazener C et al. A randomized controlled trial of pelvic floor muscle training for stages I and II pelvic organ prolapse. Int Urogynecol J Pelvic Floor Dysfunct 2009; 20: 45-51

39 Braekken IH, Majida M, Engh ME et al. Can pelvic floor muscle training reverse pelvic organ prolapse and reduce prolapse symptoms? An assessor-blinded, randomized, controlled trial. Am J Obstet Gynecol 2010; 203: 170.e1-170.e7

40 Hagen $S$, Stark $D$. Conservative prevention and management of pelvic organ prolapse in women. Cochrane Database Syst Rev 2011; (12): CD003882

41 Piya Anant $M$, Therasakvichya S, Leelaphatanadit $C$ et al. Integrated health research program for the Thai elderly: prevalence of genital prolapse and effectiveness of pelvic floor exercise to prevent worsening of genital prolapse in elderly women. J Med Assoc Thai 2003; 86: 509-515

42 Ghroubi S, Kharrat O, Chaari $M$ et al. [Effect of conservative treatment in the management of low-degree urogenital prolapse]. Ann Readapt Med Phys 2008; 51: 96-102

43 Baessler K, Junginger B. Gymnastics for urinary incontinence - destroying the myth. Neurourol Urodyn 2010; 21 (1, Suppl.): 248-249

44 Jarvis SK, Hallam TK, Lujic $S$ et al. Peri-operative physiotherapy improves outcomes for women undergoing incontinence and or prolapse surgery: results of a randomised controlled trial. Aust N Z J Obstet Gynaecol 2005; 45: 300-303

45 Frawley HC, Phillips BA, Bo K et al. Physiotherapy as an adjunct to prolapse surgery: an assessor-blinded randomized controlled trial. Neurourol Urodyn 2010; 29: 719-725

46 McClurg D, Hilton P, Dolan L et al. Pelvic floor muscle training as an adjunct to prolapse surgery: a randomised feasibility study. Int Urogynecol J 2014; 25: 883-891

47 Pauls RN, Crisp CC, Novicki Ket al. Impact of physical therapy on quality of life and function after vaginal reconstructive surgery. Female Pelvic Med Reconstr Surg 2013; 19: 271-277

48 Barber MD, Brubaker L, Burgio KL et al. Comparison of 2 transvaginal surgical approaches and perioperative behavioral therapy for apical vaginal prolapse: the OPTIMAL randomized trial. JAMA 2014; 311 : 1023-1034

49 Oliver $R$, Thakar $R$, Sultan $A H$. The history and usage of the vaginal pessary: a review. Eur J Obstet Gynecol Reprod Biol 2011; 156: 125-130

50 Sulak PJ, Kuehl TJ, Shull BL. Vaginal pessaries and their use in pelvic relaxation. J Reprod Med 1993; 38: 919-923

$51 \mathrm{Wu}$ V, Farrell SA, Baskett TF et al. A simplified protocol for pessary management. Obstet Gynecol 1997; 90: 990-994

52 Clemons JL, Aguilar VC, Sokol ER et al. Patient characteristics that are associated with continued pessary use versus surgery after 1 year. Am J Obstet Gynecol 2004; 191: 159-164

53 Sarma S, Ying T, Moore KH. Long-term vaginal ring pessary use: discontinuation rates and adverse events. BJOG 2009; 116: 1715-1721

54 Sitavarin S, Wattanayingcharoenchai R, Manonai J et al. The characteristics and satisfaction of the patients using vaginal pessaries. J Med Assoc Thai 2009; 92: 744-747

55 Lone F, Thakar R, Sultan AH et al. A 5-year prospective study of vaginal pessary use for pelvic organ prolapse. Int J Gynaecol Obstet 2011; 114: 56-59

56 Friedman S, Sandhu KS, Wang C et al. Factors influencing long-term pessary use. Int Urogynecol J 2010; 21: 673-678

57 Cundiff GW, Amundsen CL, Bent AE et al. The PESSRI study: symptom relief outcomes of a randomized crossover trial of the ring and Gellhorn pessaries. Am J Obstet Gynecol 2007; 196: 405.e1-405.e8

58 Komesu YM, Rogers RG, Rode MA et al. Pelvic floor symptom changes in pessary users. Am J Obstet Gynecol 2007; 197: 620.e1-620.e6

59 Jones K, Yang L, Lowder JL et al. Effect of pessary use on genital hiatus measurements in women with pelvic organ prolapse. Obstet Gynecol 2008; 112: 630-636

60 Clemons JL, Aguilar VC, Tillinghast TA et al. Patient satisfaction and changes in prolapse and urinary symptoms in women who were fitted 
successfully with a pessary for pelvic organ prolapse. Am J Obstet Gynecol 2004; 190: 1025-1029

61 Patel MS, Mellen C, O'Sullivan DM et al. Pessary use and impact on quality of life and body image. Female Pelvic Med Reconstr Surg 2011; 17: 298-301

62 Patel M, Mellen C, O'Sullivan DM et al. Impact of pessary use on prolapse symptoms, quality of life, and body image. Am J Obstet Gynecol 2010; 202: 499.e1-499.e4

63 Kuhn A, Bapst D, Stadlmayr W et al. Sexual and organ function in patients with symptomatic prolapse: are pessaries helpful? Fertil Steril 2009; 91: 1914-1918

64 Abdool Z, Thakar R, Sultan AH et al. Prospective evaluation of outcome of vaginal pessaries versus surgery in women with symptomatic pelvic organ prolapse. Int Urogynecol J 2011; 22: 273-278

65 Shah SM, Sultan AH, Thakar R. The history and evolution of pessaries for pelvic organ prolapse. Int Urogynecol J Pelvic Floor Dysfunct 2006; 17: 170-175

66 Chen L, Ashton-Miller JA, Hsu Y et al. Interaction among apical support, levator ani impairment, and anterior vaginal wall prolapse. Obstet Gynecol 2006; 108: 324-332

67 Dietz HP, Chantarasorn V, Shek KL. Levator avulsion is a risk factor for cystocele recurrence. Ultrasound Obstet Gynecol 2010; 36: 76-80

68 Weemhoff $M$, Vergeldt TF, Notten $K$ et al. Avulsion of puborectalis muscle and other risk factors for cystocele recurrence: a 2-year follow-up study. Int Urogynecol J 2012; 23: 65-71

69 Morgan DM, Larson K, Lewicky-Gaupp C et al. Vaginal support as determined by levator ani defect status 6 weeks after primary surgery for pelvic organ prolapse. Int J Gynaecol Obstet 2011; 114: 141-144

70 Wong V, Shek KL, Goh J et al. Cystocele recurrence after anterior colporrhaphy with and without mesh use. Eur J Obstet Gynecol Reprod Biol 2014: 172: 131-135

71 Farthmann J, Watermann D, Niesel A et al. Lower exposure rates of partially absorbable mesh compared to nonabsorbable mesh for cystocele treatment: 3-year follow-up of a prospective randomized trial. Int Urogynecol J 2013; 24: 749-758

72 Hiltunen R, Nieminen $K$, Takala T et al. Low-weight polypropylene mesh for anterior vaginal wall prolapse: a randomized controlled trial. Obstet Gynecol 2007; 110 (2 Pt 2): 455-462

73 Rapp DE, King AB, Rowe $B$ et al. Comprehensive evaluation of anterior elevate system for the treatment of anterior and apical pelvic floor descent: 2-year followup. J Urol 2014; 191: 389-394

74 de Tayrac $R$, Devoldere G, Renaudie J et al. Prolapse repair by vaginal route using a new protected low-weight polypropylene mesh: 1-year functional and anatomical outcome in a prospective multicentre study. Int Urogynecol J Pelvic Floor Dysfunct 2007; 18: 251-256

75 Rodriguez LV, Bukkapatnam R, Shah SM et al. Transvaginal paravaginal repair of high-grade cystocele central and lateral defects with concomitant suburethral sling: report of early results, outcomes, and patient satisfaction with a new technique. Urology 2005; 66 (5 Suppl.): 57-65

76 Adhoute F, Soyeur L, Pariente JL et al. [Use of transvaginal polypropylene mesh (Gynemesh) for the treatment of pelvic floor disorders in women. Prospective study in 52 patients]. Prog Urol 2004; 14: 192-196

77 Handel LN, Frenkl TL, Kim YH. Results of cystocele repair: a comparison of traditional anterior colporrhaphy, polypropylene mesh and porcine dermis. J Urol 2007; 178: 153-156

78 Borrell Palanca A, Chicote Perez F, Queipo Zaragoza JA et al. [Cystocele repair with a polypropylene mesh: our experience]. Arch Esp Urol 2004; 57: 391-396

79 Dwyer PL, O'Reilly BA. Transvaginal repair of anterior and posterior compartment prolapse with Atrium polypropylene mesh. BJOG 2004; 111: 831-836

80 Delroy CA, Castro Rde A, Dias MM et al. The use of transvaginal synthetic mesh for anterior vaginal wall prolapse repair: a randomized controlled trial. Int Urogynecol J 2013; 24: 1899-1907

81 El-Nazer MA, Gomaa IA, Ismail Madkour WA et al. Anterior colporrhaphy versus repair with mesh for anterior vaginal wall prolapse: a comparative clinical study. Arch Gynecol Obstet 2012; 286: 965-972

82 Menefee SA, Dyer KY, Lukacz ES et al. Colporrhaphy compared with mesh or graft-reinforced vaginal paravaginal repair for anterior vaginal wall prolapse: a randomized controlled trial. Obstet Gynecol 2011; 118: $1337-1344$

83 Natale F, La Penna C, Padoa A et al. A prospective, randomized, controlled study comparing Gynemesh, a synthetic mesh, and Pelvicol, a biologic graft, in the surgical treatment of recurrent cystocele. Int Urogynecol J Pelvic Floor Dysfunct 2009; 20: 75-81
84 Sivaslioglu AA, Unlubilgin E, Dolen I. A randomized comparison of polypropylene mesh surgery with site-specific surgery in the treatment of cystocoele. Int Urogynecol J Pelvic Floor Dysfunct 2008; 19: 467-471

85 Turgal M, Sivaslioglu A, Yildiz A et al. Anatomical and functional assessment of anterior colporrhaphy versus polypropylene mesh surgery in cystocele treatment. Eur J Obstet Gynecol Reprod Biol 2013; 170: $555-558$

86 Milani R, Salvatore S, Soligo $M$ et al. Functional and anatomical outcome of anterior and posterior vaginal prolapse repair with prolene mesh. BJOG 2005; 112: 107-111

87 Hung MJ, Liu FS, Shen PS et al. Factors that affect recurrence after anterior colporrhaphy procedure reinforced with four-corner anchored polypropylene mesh. Int Urogynecol J Pelvic Floor Dysfunct 2004; 15 : 399-406; discussion 406

88 Bader G, Fauconnier A, Roger $N$ et al. [Cystocele repair by vaginal approach with a tension-free transversal polypropylene mesh. Technique and results]. Gynecol Obstet Fertil 2004; 32: 280-284

89 de Tayrac R, Deffieux X, Gervaise A et al. Long-term anatomical and functional assessment of trans-vaginal cystocele repair using a tension-free polypropylene mesh. Int Urogynecol J Pelvic Floor Dysfunct 2006; 17: 483-488

90 Wong $V$, Shek K, Rane A et al. Is levator avulsion a predictor of cystocele recurrence following anterior vaginal mesh placement? Ultrasound Obstet Gynecol 2013; 42: 230-234

91 Meschia M, Pifarotti P, Bernasconi F et al. Porcine skin collagen implants to prevent anterior vaginal wall prolapse recurrence: a multicenter, randomized study. J Urol 2007; 177: 192-195

92 Hosni MM, El-Feky AE, Agur WI et al. Evaluation of three different surgical approaches in repairing paravaginal support defects: a comparative trial. Arch Gynecol Obstet 2013; 288: 1341-1348

93 Leone Roberti Maggiore U, Ferrero S, Mancuso S et al. Feasibility and outcome of vaginal paravaginal repair using the Capio suture-capturing device. Int Urogynecol J 2012; 23: 341-347

94 Viana R, Colaco J, Vieira A et al. Cystocele - vaginal approach to repairing paravaginal fascial defects. Int Urogynecol J Pelvic Floor Dysfunct 2006: 17: 621-623

95 Mallipeddi PK, Steele AC, Kohli $N$ et al. Anatomic and functional outcome of vaginal paravaginal repair in the correction of anterior vaginal wall prolapse. Int Urogynecol J Pelvic Floor Dysfunct 2001; 12: 83-88

96 Grody MHT, Nyirjesy P, Kelley LM et al. Paraurethral fascial sling urethropexy and vaginal paravaginal defects cystopexy in the correction of urethrovesical prolapse. Int Urogynecol J Pelvic Floor Dysfunct 1995; 6: 80-85

97 Shull BL, Benn SJ, Kuehl TJ. Surgical management of prolapse of the anterior vaginal segment: an analysis of support defects, operative morbidity, and anatomic outcome. Am J Obstet Gynecol 1994; 171: 1429 1436; discussion 1436-1439

98 Bruce RG, El-Galley RE, Galloway NT. Paravaginal defect repair in the treatment of female stress urinary incontinence and cystocele. Urology 1999; 54: 647-651

99 Bruce RG, El Galley RE, Galloway NT. Paravaginal defect repair in the treatment of female stress urinary incontinence and cystocele. Urology 1999; 54: 647-651

100 Bai SW, Jeon JD, Chung KA et al. The effectiveness of modified six-corner suspension in patients with paravaginal defect and stress urinary incontinence. Int Urogynecol J Pelvic Floor Dysfunct 2002; 13: 303307

101 Demirci F, Ozdemir I, Somunkiran A et al. Abdominal paravaginal defect repair in the treatment of paravaginal defect and urodynamic stress incontinence. J Obstet Gynaecol 2007; 27: 601-604

102 Richardson AC, Edmonds PB, Williams NL. Treatment of stress urinary incontinence due to paravaginal fascial defect. Obstet Gynecol 1981; 57: 357-362

103 Behnia-Willison F, Seman EI, Cook JR et al. Laparoscopic paravaginal repair of anterior compartment prolapse. J Minim Invasive Gynecol 2007; 14: 475-480

104 Kahn MA, Stanton SL, Kumar D et al. Posterior colporrhaphy is superior to the transanal repair for treatment of posterior vaginal wall prolapse. Neurourol Urodyn 1999; 18: 70-71

105 Kahn MA, Stanton SL. Posterior colporrhaphy: its effects on bowel and sexual function. Br J Obstet Gynaecol 1997; 104: 82-86

106 Mellgren A, Anzen B, Nilsson BY et al. Results of rectocele repair. A prospective study. Dis Colon Rectum 1995; 38: 7-13 
107 Nieminen K, Hiltunen KM, Laitinen J et al. Transanal or vaginal approach to rectocele repair: a prospective, randomized pilot study. Dis Colon Rectum 2004; 47: 1636-1642

108 DeLancey JO. Anatomic aspects of vaginal eversion after hysterectomy. Am J Obstet Gynecol 1992; 166 (6 Pt 1): 1717-1724; discussion $1724-1728$

109 Margulies RU, Rogers MA, Morgan DM. Outcomes of transvaginal uterosacral ligament suspension: systematic review and metaanalysis. Am J Obstet Gynecol 2010; 202: 124-134

110 Bedford ND, Seman EI, O'Shea RT et al. Effect of uterine preservation on outcome of laparoscopic uterosacral suspension. J Minim Invasive Gynecol 2013; 20: 172-177

111 Lin LL, Phelps JY, Liu CY. Laparoscopic vaginal vault suspension using uterosacral ligaments: a review of 133 cases. J Minim Invasive Gynecol 2005; 12: 216-220

112 Nygaard IE, McCreery R, Brubaker L et al. Abdominal sacrocolpopexy: a comprehensive review. Obstet Gynecol 2004; 104: 805-823

113 Maher CF, Feiner B, DeCuyper EM et al. Laparoscopic sacral colpopexy versus total vaginal mesh for vaginal vault prolapse: a randomized trial. Am J Obstet Gynecol 2011; 204: 360.e1-360.e7

114 Natale F, La Penna C, Padoa A et al. High levator myorraphy versus uterosacral ligament suspension for vaginal vault fixation: a prospective, randomized study. Int Urogynecol J Pelvic Floor Dysfunct 2010; 21: 515-522

115 Hullfish KL, Bovbjerg VE, Steers WD. Colpocleisis for pelvic organ prolapse: patient goals, quality of life, and satisfaction. Obstet Gynecol 2007; 110 (2 Pt 1): 341-345

116 Vij M, Bombieri L, Dua A et al. Long-term follow-up after colpocleisis: regret, bowel, and bladder function. Int Urogynecol J 2014; 25: 811815

117 Crisp CC, Book NM, Smith AL et al. Body image, regret, and satisfaction following colpocleisis. Am J Obstet Gynecol 2013; 209: 473.e1-473.e7

118 Jelovsek JE, Chagin K, Brubaker L et al. A model for predicting the risk of de novo stress urinary incontinence in women undergoing pelvic organ prolapse surgery. Obstet Gynecol 2014; 123 (2 Pt 1): 279-287

119 Baessler K, Maher C. Pelvic organ prolapse surgery and bladder function. Int Urogynecol J 2013; 24: 1843-1852

120 Nieminen K, Hiltunen R, Takala T et al. Outcomes after anterior vaginal wall repair with mesh: a randomized, controlled trial with a 3 year follow-up. Am J Obstet Gynecol 2010; 203: 235.e1-235.e8

121 Brubaker L, Cundiff GW, Fine P et al. Abdominal sacrocolpopexy with Burch colposuspension to reduce urinary stress incontinence. N Engl J Med 2006; 354: 1557-1566

122 Hviid U, Hviid TV, Rudnicki M. Porcine skin collagen implants for anterior vaginal wall prolapse: a randomised prospective controlled study. Int Urogynecol J 2010; 21: 529-534

123 Colombo M, Vitobello D, Proietti $F$ et al. Randomised comparison of Burch colposuspension versus anterior colporrhaphy in women with stress urinary incontinence and anterior vaginal wall prolapse. BJOG 2000; 107: 544-551

124 Sentilhes L, Sergent F, Resch B et al. Midterm follow-up of high-grade genital prolapse repair by the trans-obturator and infracoccygeal hammock procedure after hysterectomy. Eur Urol 2007; 51: 10651072

125 Sergent F, Gay-Crosier G, Bisson V et al. Ineffectiveness of associating a suburethral tape to a transobturator mesh for cystocele correction on concomitant stress urinary incontinence. Urology 2009; 74: 765-770

126 Sergent $F$, Zanati J, Bisson $V$ et al. Perioperative course and mediumterm outcome of the transobturator and infracoccygeal hammock for posthysterectomy vaginal vault prolapse. Int J Gynaecol Obstet 2010; 109: 131-135

127 Feiner B, Gietelink L, Maher C. Anterior vaginal mesh sacrospinous hysteropexy and posterior fascial plication for anterior compartment dominated uterovaginal prolapse. Int Urogynecol J 2010; 21: 203208

128 Fayyad AM, North C, Reid FM et al. Prospective study of anterior transobturator mesh kit (Prolift) for the management of recurrent anterior vaginal wall prolapse. Int Urogynecol J 2010; 22: 157-163

129 Takahashi S, Obinata D, Sakuma T et al. Tension-free vaginal mesh procedure for pelvic organ prolapse: a single-center experience of 310 cases with 1-year follow up. Int J Urol 2010; 17: 353-358

130 Borstad E, Abdelnoor M, Staff AC et al. Surgical strategies for women with pelvic organ prolapse and urinary stress incontinence. Int Urogynecol J 2010; 21: 179-186
131 Schierlitz L, Dwyer P, Rosamilia A et al. A prospective randomised controlled study comparing vaginal prolapse repair with and without tension free vaginal tape (TVT) in women with severe pelvic organ prolapse and occult stress incontinence (Abstract number 114). Neurourol Urodyn 2007; 26: 743-744

132 Meschia M, Pifarotti P, Spennacchio $M$ et al. A randomized comparison of tension-free vaginal tape and endopelvic fascia plication in women with genital prolapse and occult stress urinary incontinence. Am J Obstet Gynecol 2004; 190: 609-613

133 Wei J. A midurethral sling prevents incontinence among women undergoing vaginal prolapse repair-the OPUS trial (Abstract). Neurourol Urodyn 2011; DOI: 10.1056/NEJMoa1111967

134 Nygaard I, Brubaker L, Zyczynski HM et al. Long-term outcomes following abdominal sacrocolpopexy for pelvic organ prolapse. JAMA 2013; 309: 2016-2024

135 Sung VW, Rogers RG, Schaffer JI et al. Graft use in transvaginal pelvic organ prolapse repair: a systematic review. Obstet Gynecol 2008; 112: $1131-1142$

136 Abed H, Rahn DD, Lowenstein L et al. Incidence and management of graft erosion, wound granulation, and dyspareunia following vaginal prolapse repair with graft materials: a systematic review. Int Urogynecol J 2011; 22: 789-798

137 Araco F, Gravante G, Sorge R et al. The influence of BMI, smoking, and age on vaginal erosions after synthetic mesh repair of pelvic organ prolapses. A multicenter study. Acta Obstet Gynecol Scand 2009; 88: 772-780

138 Deffieux X, Letouzey V, Savary D et al. Prevention of complications related to the use of prosthetic meshes in prolapse surgery: guidelines for clinical practice. Eur J Obstet Gynecol Reprod Biol 2012; 165: 170180

139 Araco F, Gravante G, Piccione E. Bladder erosion after 2 years from cystocele repair with type I polypropylene mesh. Int Urogynecol J Pelvic Floor Dysfunct 2009; 20: 731-733

140 Cundiff GW, Varner E, Visco AG et al. Risk factors for mesh/suture erosion following sacral colpopexy. Am J Obstet Gynecol 2008; 199; 688.e1-688.e5

141 Lowman JK, Woodman PJ, Nosti PA et al. Tobacco use is a risk factor for mesh erosion after abdominal sacral colpoperineopexy. Am J Obstet Gynecol 2008; 198: 561.e1-561.e4

142 Withagen MI, Vierhout ME, Hendriks JC et al. Risk factors for exposure, pain, and dyspareunia after tension-free vaginal mesh procedure. Obstet Gynecol 2011; 118: 629-636

143 Abdel-Fattah M, Ramsay I. Retrospective multicentre study of the new minimally invasive mesh repair devices for pelvic organ prolapse. BJOG 2008; 115: 22-30

144 Feiner B, Maher C. Vaginal mesh contraction: definition, clinical presentation, and management. Obstet Gynecol 2010; 115 (2 Pt 1): 325-330

145 Moore RD, Beyer RD, Jacoby K et al. Prospective multicenter trial assessing type I, polypropylene mesh placed via transobturator route for the treatment of anterior vaginal prolapse with 2-year follow-up. Int Urogynecol J Pelvic Floor Dysfunct 2010; 21: 545-552

146 Achtari C, Hiscock R, O'Reilly BA et al. Risk factors for mesh erosion after transvaginal surgery using polypropylene (Atrium) or composite polypropylene/polyglactin 910 (Vypro II) mesh. Int Urogynecol J Pelvic Floor Dysfunct 2005; 16: 389-394

147 Cervigni M, Natale F, La Penna C et al. Collagen-coated polypropylene mesh in vaginal prolapse surgery: an observational study. Eur J Obstet Gynecol Reprod Biol 2011; 156: 223-227

148 Collinet $P$, Belot F, Debodinance $P$ et al. Transvaginal mesh technique for pelvic organ prolapse repair: mesh exposure management and risk factors. Int Urogynecol J Pelvic Floor Dysfunct 2006; 17: 315-320

149 Deffieux X, de Tayrac R, Huel C et al. Vaginal mesh erosion after transvaginal repair of cystocele using Gynemesh or Gynemesh-Soft in 138 women: a comparative study. Int Urogynecol J Pelvic Floor Dysfunct 2007; 18: 73-79

150 Blandon RE, Gebhart JB, Trabuco EC et al. Complications from vaginally placed mesh in pelvic reconstructive surgery. Int Urogynecol J Pelvic Floor Dysfunct 2009; 20: 523-531

151 Diwadkar GB, Barber MD, Feiner B et al. Complication and reoperation rates after apical vaginal prolapse surgical repair: a systematic review. Obstet Gynecol 2009; 113 (2 Pt 1): 367-373

152 Abbott S, Unger CA, Evans JM et al. Evaluation and management of complications from synthetic mesh after pelvic reconstructive surgery: a multicenter study. Am J Obstet Gynecol 2014; 210: 163.e1-163.e8 
Guideline Program

\section{Editors}

Leading Professional Medical Associations

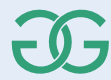

German Society of Gynecology and Obstetrics (Deutsche Gesellschaft für Gynäkologie und Geburtshilfe e. V. [DGGG])

Head Office of DGGG and Professional Societies Hausvogteiplatz 12

DE-10117 Berlin

info@dggg.de

http://www.dggg.de/

President of DGGG

Prof. Dr. Birgit Seelbach-Göbel

Universität Regensburg

Klinik für Geburtshilfe und Frauenheilkunde

St. Hedwig-Krankenhaus Barmherzige Brüder

Steinmetzstraße 1-3

DE-93049 Regensburg

\section{DGGG Guidelines Representative}

Prof. Dr. med. Matthias W. Beckmann

Universitätsklinikum Erlangen

Frauenklinik

Universitätsstraße 21-23

DE-91054 Erlangen

\section{Guidelines Coordination}

Dr. med. Paul Gaß, Tobias Brodkorb, Marion Gebhardt Universitätsklinikum Erlangen

Frauenklinik

Universitätsstraße 21-23

DE-91054 Erlangen

fk-dggg-leitlinien@uk-erlangen.de

http://www.dggg.de/leitlinienstellungnahmen

\section{OEGGE}

Austrian Society of Gynecology and Obstetrics (Österreichische Gesellschaft für Gynäkologie und Geburtshilfe [OEGGG])

Innrain 66A

AT-6020 Innsbruck

stephanie.leutgeb@oeggg.at

http://www.oeggg.at

\section{President of OEGGG}

Prof. Dr. med. Petra Kohlberger

Universitätsklinik für Frauenheilkunde Wien

Währinger Gürtel 18-20

AT-1180 Wien

\section{OEGGG Guidelines Representative}

Prof. Dr. med. Karl Tamussino

Universitätsklinik für Frauenheilkunde

und Geburtshilfe Graz

Auenbruggerplatz 14

AT-8036 Graz

\section{gynécologie}

suisse

Swiss Society of Gynecology and Obstetrics (Schweizerische Gesellschaft für Gynäkologie und Geburtshilfe [SGGG])

Gynécologie Suisse SGGG

Altenbergstraße 29

Postfach 6

CH-3000 Bern 8

sekretariat@sggg.ch

http://www.sggg.ch/

President of SGGG

Dr. med. David Ehm

FMH für Geburtshilfe und Gynäkologie

Nägeligasse 13

CH-3011 Bern

SGGG Guidelines Representative

Prof. Dr. med. Daniel Surbek

Universitätsklinik für Frauenheilkunde

Geburtshilfe und feto-maternale Medizin

Inselspital Bern

Effingerstraße 102

CH-3010 Bern 